\title{
BMJ Open Association between medication adherence and non-drug healthcare utilisation and costs: a retrospective longitudinal cohort study among US women age 65 and older
}

\author{
Siyu Ma (D) , ${ }^{1}$ Donald S Shepard (D) , ${ }^{2}$ Grant A Ritter, ${ }^{2}$ Robert E Martell, ${ }^{3}$ \\ Cindy Thomas ${ }^{2}$
}

To cite: Ma S, Shepard DS, Ritter GA, et al. Association between medication adherence and non-drug healthcare utilisation and costs: a retrospective longitudinal cohort study among US women age 65 and older. BMJ Open 2021;11:e052146. doi:10.1136/ bmjopen-2021-052146

- Prepublication history and additional supplemental material for this paper are available online. To view these files, please visit the journal online (http://dx.doi.org/10.1136/ bmjopen-2021-052146).

Received 06 April 2021 Accepted 18 October 2021

Check for updates

(C) Author(s) (or their employer(s)) 2021. Re-use permitted under CC BY-NC. No commercial re-use. See rights and permissions. Published by BMJ.

${ }^{1}$ Center for the Evaluation of Value and Risk in Health, Tufts Medical Center, Boston, Massachusetts, USA

${ }^{2}$ The Heller School for Social Policy and Management, Brandeis University, Waltham, Massachusetts, USA

${ }^{3}$ Hematology/Oncology, Tufts Medical Center, Boston,

Massachusetts, USA

Correspondence to

Dr Siyu Ma; masy@brandeis.edu

\section{ABSTRACT}

Objectives To explore the association between hormone therapy $(\mathrm{HT})$ adherence and non-drug healthcare utilisation and healthcare costs among patients with breast cancer. Design Retrospective longitudinal cohort study. Setting The US Medicare beneficiaries in the SEERMedicare-linked database

Participants Women aged $\geq 65$ with hormone-receptor positive breast cancer from 2007 through mid-2009 in the USA.

Interventions We examined the relationship between $\mathrm{HT}$ and adherence and outcomes of our interests.

Primary and secondary outcome measures Our study cohort's HT adherence, non-drug healthcare utilisation and healthcare costs for the first year of $\mathrm{HT}$ and each year, thereafter, for a total of 5 years.

Results 6045 eligible Medicare beneficiaries that met our selection criteria were included. We found that patients who were adherent to HT were associated with lower healthcare utilisation of all kinds (inpatient ( 0.35 vs 0.43 , $p<0.001$ ), length of study during hospitalisation (4.19 vs $4.89, p<0.01$ ), physician office visits ( 25.16 vs 26.17 , $\mathrm{p}<0.001)$ ), and significant reductions in many types of medical costs and neutral total healthcare costs despite the increased pharmacy costs. Half of the total medical cost reduction came from savings in hospitalisation costs. Conclusions Our study suggests that the added cost of HT adherence was all but offset by the reduced cost for other medical care. Our study provides evidence on the potential success of implementing value-based insurance design (VBID) plans among patients with breast cancer to improve their long-term oral medication adherence. Policymakers should consider adherence improvement strategies such as VBID plans, given that the costs likely will not surpass the total savings.

\section{INTRODUCTION}

Breast cancer is the most commonly diagnosed non-skin cancer among US women, representing $30 \%$ of all new cancer cases in 2020. ${ }^{1}$ With improved screening and treatment, the US breast cancer death rate has

\section{Strength and limitations of this study}

- First of its kind to reveal the association between hormone therapy adherence and non-drug healthcare utilisation and costs among Medicare patients with breast cancer in the USA over the full course of 5-year treatment.

- Provided insights into the potential benefits of implementing value-based insurance design plans among patients with breast cancer to improve their long-term oral medication adherence.

- Unable to precisely calculate the filled prescriptions or the drug costs due to data limitations.

been decreasing by $1.8 \%$ each year over the past decade, and the current 5-year survival rate is about $90 \% .^{2}$ As more patients are living with breast cancer, the associated healthcare costs have also been increasing. Breast cancer accounts for the largest share of national expenditure for cancer care. It increased from US $\$ 16.5$ billion in 2010 to US $\$ 19.7$ billion in 2018. ${ }^{3}$

Hormone receptor (HR)-positive breast cancer subtype accounts for over $80 \%$ of total breast cancer. Among HR-positive patients with breast cancer, adjuvant endocrine (or hormone) therapy has been incorporated as part of the treatment regime after surgical removal of the tumour. ${ }^{4-7}$ There are several types of hormone therapy (HT) medications, including tamoxifen and aromatase inhibitors (AIs). AIs are a newer generation of adjuvant HT medications for postmenopausal women, including anastrozole, letrozole and exemestane. Clinical evidence showed that AIs are more effective than tamoxifen in improving survival and reducing disease recurrence among postmenopausal women. ${ }^{8}$ In order to achieve the most desired health benefits, the 
American Society of Clinical Oncology recommended HT treatment for at least 5 years. ${ }^{9}$ However, long-term HT adherence remains suboptimal. This is problematic, because failure to complete a full course of treatment compromises health benefits and often results in treatment failure. ${ }^{10-12}$

Previous studies showed that improved medication adherence may associate with lower total healthcare costs, even though it may increase pharmacy costs. The increase in pharmacy costs due to medication adherence is often offset by savings in other non-drug medical costs, as overall health improves. ${ }^{13-15}$ For example, in a four-state study of dual eligible Medicare/Medicaid beneficiaries with congestive heart failure (CHF), patients who were found to be adherent to their prescribed medication regimes were $4 \%$ less likely to be hospitalised and $3.0 \%$ less likely to visit the emergency department (ED). In total, their total healthcare costs per year were US\$5910 (23\%) lower than beneficiaries found to be non-adherent. ${ }^{16}$ Roebuck et al examined privately insured patients with four chronic conditions (CHF, hypertension, diabetes and dyslipidaemia) and found that medication adherence was associated with 1.18 (for dyslipidaemia) to 5.72 (for CHF) fewer days in inpatient stays, 0.01 to 0.04 reduction in ED visits and a corresponding US $\$ 1258$ (for dyslipidaemia) to US\$7823 (for CHF) reduction in total annual healthcare. ${ }^{15}$ Boye $e t a l^{17}$ examined patients with type 2 diabetes and found that every $1 \%$ increase in medication adherence was associated with on average US\$65464 all-cause cost savings among 1000 patients, similarly driven by the lowered probability of hospitalisations and ED visits.

While a myriad of studies have found an inverse relationship between medication adherence and non-drug healthcare utilisation and total healthcare costs, most of them focused on chronic cardiovascular diseases. Only a few studies explored the association between medication adherence and non-drug healthcare utilisations and costs among patients with breast cancer. One 4-year longitudinal study of Medicaid beneficiaries with breast cancer from South Carolina found that HT adherence was associated with $31 \%$ decrease in medical costs, but no significant savings in total healthcare cost. The different results between medical and total healthcare costs could be due to adverse events associated with long-term use of HT. ${ }^{18}$ While this finding was informative, more research focusing on patients with breast cancer among a broader sample of Medicare beneficiaries are needed. In this study, we used a nationally representative sample of Medicare beneficiaries to examine the relationships between HT adherence and non-drug healthcare utilisation and healthcare costs. The objective of our study is to answer the research questions of what are the association between HT adherence and non-drug healthcare utilisation and healthcare costs among patients with breast cancer? We hypothesise that the non-drug healthcare utilisation will be lower among patients with breast cancer who adhere to HT compared with those who do not. Furthermore, HT adherent patients will have higher prescription drug costs, but lower non-drug costs and lower or no difference in total healthcare costs compared with non-adherent patients.

\section{METHOD}

\section{Data source}

We used SEER-Medicare linked database for the years 2007-2014. The National Cancer Institute's SEER database is the only database that includes comprehensive population-based information on breast cancer patients' demographics, cancer diagnosis, time of diagnosis and initial therapy (surgery and/or radiation). At the time of this study, SEER covered $34.6 \%$ of the US population. The linked Medicare component includes beneficiaries'

\begin{tabular}{|c|c|}
\hline Characteristics & Number $(\%)^{*}$ \\
\hline Median age, years (range) & $74.6(65-103)$ \\
\hline \multicolumn{2}{|l|}{ Age group } \\
\hline $65-69$ & 1748 (28.9) \\
\hline $70-74$ & $1537(25.4)$ \\
\hline $75-79$ & $1242(20.6)$ \\
\hline $80+$ & $1518(25.1)$ \\
\hline \multicolumn{2}{|l|}{ Race/ethnicity } \\
\hline White, non-Hispanic & $5068(83.8)$ \\
\hline Black & $392(6.5)$ \\
\hline Hispanic & 334 (5.5) \\
\hline Asian & $251(4.2)$ \\
\hline \multicolumn{2}{|l|}{ Comorbidity (HCC score) } \\
\hline 0 & 2098 (36.9) \\
\hline 1 & $1504(26.5)$ \\
\hline 2 & 918 (16.2) \\
\hline $3+$ & $1161(20.4)$ \\
\hline \multicolumn{2}{|l|}{ Marital status } \\
\hline Married & $2570(42.5)$ \\
\hline Unmarried & $3475(57.5)$ \\
\hline \multicolumn{2}{|l|}{ Tumour stage } \\
\hline 1 & 3297 (54.5) \\
\hline II & $2124(35.1)$ \\
\hline III & $624(10.3)$ \\
\hline \multicolumn{2}{|l|}{ Treatment } \\
\hline Surgery +radiation & $3155(52.2)$ \\
\hline Surgery, no radiation & $2709(44.8)$ \\
\hline No surgery & $181(3.0)$ \\
\hline
\end{tabular}

*Values are number (percentage) unless indicated otherwise. HCC, Hierarchical Condition Category. 
Table 2 Hormone therapy adherence, healthcare utilisation and costs over the full course of aromatase inhibitor treatment among Medicare beneficiaries with breast cancer

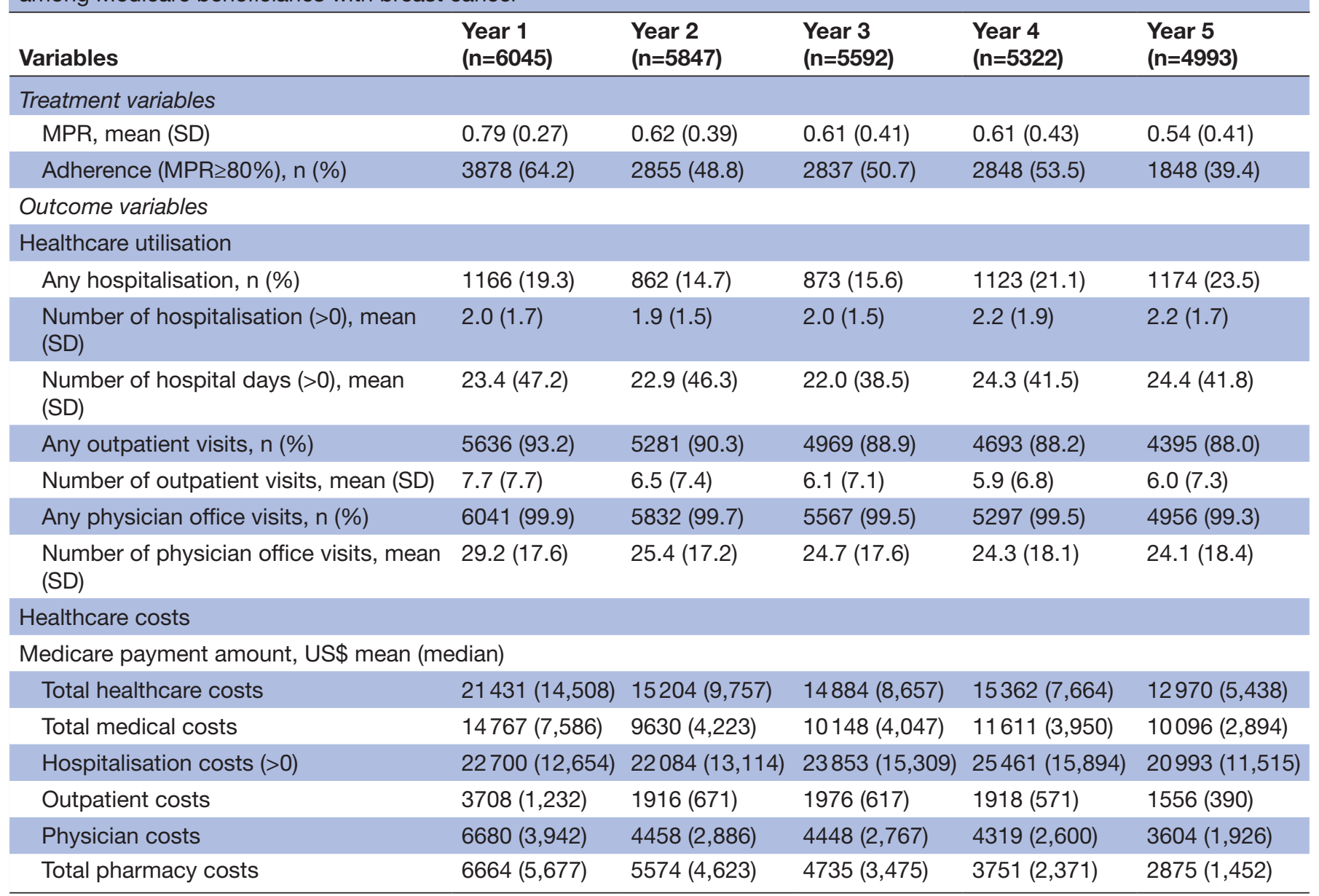

MPR, medication possession ratio.

enrolment, prescription drug use and costs and non-drug healthcare utilisation and costs information. ${ }^{19}$

\section{Study sample}

Our study sample is women diagnosed with HR-positive early stage breast cancer in years from 2007 to mid-2009 in the USA. Other criteria for inclusion were: (1) 65 years or older, (2) no missing race value, (3) with only one breast cancer diagnosis within the study period, (4) initiated AI treatment within the first year of breast cancer diagnosis, (5) continuously enrolled in Medicare Part A and Part B and Part D from diagnosis data through 5 years after the first-filled AI prescription or until dead, whichever came first (gaps of 45 days or less allowed), (6) did not spend a full year in an inpatient facility (ie, hospital or skilled nurse facility). The screening process for constructing our study cohort is found in supplementary material (online supplemental appendix A).

\section{Variables}

Dependent variables

We examined the non-drug healthcare utilisation and healthcare costs for the patients' first year of AI treatment and each year, thereafter, for a total of 5 years (year
1 through year 5). Variables of non-drug healthcare utilisation included any hospitalisation, length of stay (LOS), and numbers of inpatient, outpatient (including unplanned emergency room visits) and physician office visits. Healthcare costs included all-cause non-drug medical costs (inpatient, outpatient and physician office visits costs), all-cause prescription costs and the sum of the two as total healthcare costs. All costs were measured by the total amount paid by Medicare and standardised to 2014 dollars using the medical care component of the consumer price index (https://www.bls.gov/cpi/).

\section{Treatment variables}

A patient's adherence to AI treatment was based on the medication possession ratio (MPR), calculated as the number of days of AI supplied divided by the number of days covered in a year. A patient's inpatient days were excluded from the denominator because AI medications may have come from another source during an inpatient stay and not be reflected in Medicare part D data. Each patient had an update to five MPRs: first year of AI treatment and each year, thereafter, for a total of 5years (year 1 through year 5). If a patient died, he/she was excluded from the following years. MPR values in 
Table 3 Unadjusted annual healthcare utilisation and costs in adherent and nonadherent Medicare beneficiaries with breast cancer over the full course of treatment

\begin{tabular}{|c|c|c|c|}
\hline Variables & Adherent & Non-adherent & $\mathbf{P}$ \\
\hline \multicolumn{4}{|c|}{ Healthcare utilisation } \\
\hline \multicolumn{4}{|c|}{ Any hospitalisation, n (\%) } \\
\hline Year 1 & $729(18.8)$ & $437(20.2)$ & NS \\
\hline Year 2 & $395(13.8)$ & $467(15.6)$ & NS \\
\hline Year 3 & $404(14.2)$ & $469(17.0)$ & $<0.01$ \\
\hline Year 4 & $521(18.3)$ & $602(24.3)$ & $<0.001$ \\
\hline Year 5 & $417(21.2)$ & $757(25.0)$ & $<0.01$ \\
\hline \multicolumn{4}{|c|}{ Number of hospitalisation $(>0)$, mean (SD) } \\
\hline Year 1 & $2.0(1.7)$ & $2.1(1.7)$ & NS \\
\hline Year 2 & $1.8(1.4)$ & $2.0(1.5)$ & NS \\
\hline Year 3 & $2.0(1.4)$ & $2.0(1.5)$ & NS \\
\hline Year 4 & $2.1(1.8)$ & $2.2(1.9)$ & NS \\
\hline Year 5 & $2.1(1.8)$ & $2.2(1.7)$ & NS \\
\hline \multicolumn{4}{|c|}{ Number of hospital days $(>0)$, mean $(\mathrm{SD})$} \\
\hline Year 1 & $25.5(53.8)$ & $19.9(33.0)$ & $<0.05$ \\
\hline Year 2 & $22.3(49.4)$ & $23.5(43.5)$ & NS \\
\hline Year 3 & $23.3(41.8)$ & $20.8(35.3)$ & NS \\
\hline Year 4 & $24.8(45.7)$ & $23.8(37.6)$ & NS \\
\hline Year 5 & $23.7(38.0)$ & $24.8(43.8)$ & NS \\
\hline \multicolumn{4}{|c|}{ Any outpatient visits, n (\%) } \\
\hline Year 1 & $3612(93.1)$ & $2024(93.4)$ & NS \\
\hline Year 2 & $2600(91.1)$ & 2681 (89.6) & NS \\
\hline Year 3 & $2537(89.4)$ & $2432(88.3)$ & NS \\
\hline Year 4 & $2564(90.0)$ & $2129(86.1)$ & $<0.001$ \\
\hline Year 5 & $1766(89.8)$ & 2629 (86.9) & $<0.01$ \\
\hline \multicolumn{4}{|c|}{ Number of outpatient visits, mean (SD) } \\
\hline Year 1 & $7.7(7.6)$ & $7.9(7.9)$ & NS \\
\hline Year 2 & $6.5(7.4)$ & $6.4(7.4)$ & NS \\
\hline Year 3 & $6.2(7.2)$ & $6.0(7.0)$ & NS \\
\hline Year 4 & $5.9(6.8)$ & $5.9(6.8)$ & NS \\
\hline Year 5 & $6.1(7.2)$ & $5.9(7.4)$ & NS \\
\hline \multicolumn{4}{|c|}{ Number of physician office visits, mean (SD) } \\
\hline Year 1 & $28.5(17.3)$ & $30.3(18.1)$ & $<0.001$ \\
\hline Year 2 & $25.2(16.8)$ & $25.6(17.5)$ & NS \\
\hline Year 3 & $24.4(16.5)$ & $25.0(18.6)$ & NS \\
\hline Year 4 & $23.9(17.3)$ & $24.9(18.9)$ & $<0.05$ \\
\hline Year 5 & $23.8(18.1)$ & $24.3(18.5)$ & NS \\
\hline \multicolumn{4}{|c|}{ Healthcare costs } \\
\hline \multicolumn{4}{|c|}{ Medicare payment amount } \\
\hline \multicolumn{4}{|c|}{ Total healthcare costs, US\$ mean (median) } \\
\hline Year 1 & $22025(15,502)$ & $20370(12,604)$ & $<0.01$ \\
\hline Year 2 & $16624(11,434)$ & $13849(8,072)$ & $<0.001$ \\
\hline Year 3 & $15110(9,865)$ & $14651(7,488)$ & NS \\
\hline Year 4 & $14563(7,906)$ & $16283(7,347)$ & $<0.01$ \\
\hline
\end{tabular}

Continued 
Table 3 Continued

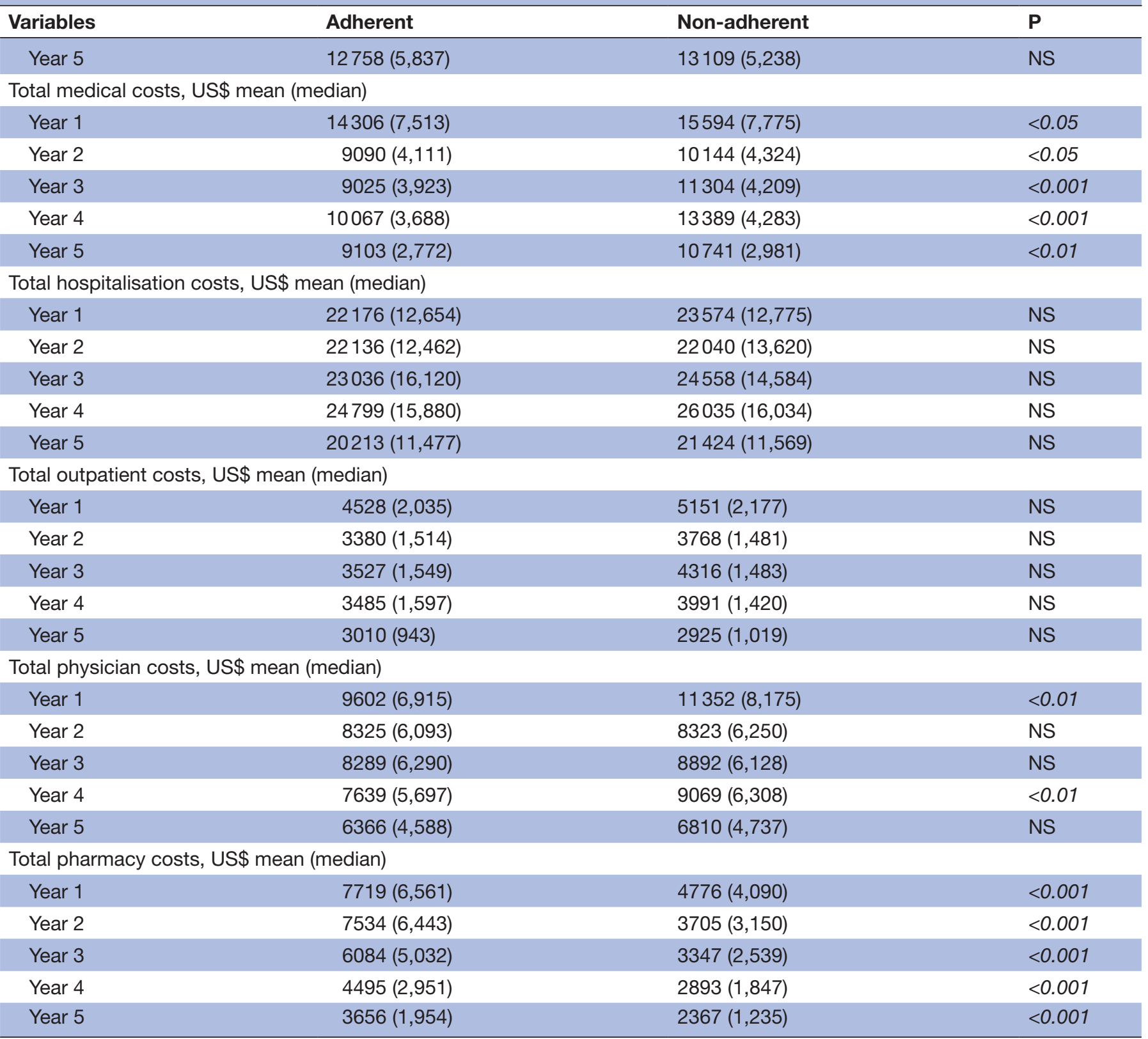

Note: NS stands for not significant.

years when patients were alive but did not fill any AI prescriptions were set to 0 . MPR as capped at $100 \%$ if numerator is greater than denominator due to early refills. As a sensitivity analysis, we also analysed an 'adherence' indicator variable with value 1 , if the patient's MPR for the year was $80 \%$ or more. ${ }^{20-24}$

\section{Covariates}

Time-invariant covariates used in our analyses included a patient's race/ethnicity, marital status, tumour stage and certain treatment characteristics. Two time-variant covariates were included in our analyses: patient's age at the start of each year (years 1 through year 5); and the patient's Hierarchical Condition Category (HCC) score. HCG score is a risk adjustment factor based on a patient's comorbidities. Our analyses also included variables representing calendar years to address the concurrent trends in healthcare utilisation and costs. The descriptions of full list of our variables are shown in supplementary material (online supplemental appendix B).

\section{Data analysis}

We first examined the distributions of all independent variables, including patients' MPR and adherence value and then calculated summary statistics on outcomes each year (year 1 through year 5): any hospitalisation (yes or no) or outpatient visits (yes or no), numbers of inpatient stays, number of outpatient clinic visits or number physician office visits and mean LOS associated with hospitalisation. We also calculated the average healthcare costs to 
Table 4 Adjusted healthcare utilisation and costs among Medicare beneficiaries with breast cancer over the full course of treatment

\begin{tabular}{lll}
\hline Variables & MPR $^{*}$ & $\mathbf{P}$ \\
\hline Healthcare utilisation & & \\
Number of hospitalisations $\dagger$ & -0.009 & $<0.001$ \\
\hline Number of hospital days & -0.088 & $<0.01$ \\
\hline Number of outpatient visits & -0.018 & NS \\
Number of physician office visits & -0.111 & $<0.001$ \\
Healthcare costs & & \\
Medicare payment amount & & \\
\hline Total healthcare costs & 51 & NS \\
\hline Total medical costs & -281 & $<0.001$ \\
\hline Total hospitalisation costs & -109 & $<0.001$ \\
\hline Total outpatient costs & -52 & $<0.001$ \\
\hline Total physician costs & -105 & $<0.001$ \\
\hline Total pharmacy costs & 365 & $<0.001$ \\
\hline
\end{tabular}

Notes: NS stands for not significant.

${ }^{*}$ The prediction model controlled for other covariate, full results see online supplemental material (online supplemental appendix C). †An example for interpreting the finding: every $10 \%$ increase in MPR was associated with 0.009 less number of hospitalisations $(\mathrm{p}<0.001)$.

MPR, medication possession ratio.

Medicare including non-drug medical costs, prescription drug costs and total healthcare costs.

Based on preliminary descriptive and bivariate analyses, we determined the appropriate statistical modelling methods for each of our outcome measures as described in the following and selected covariates to include as adjustors. Zero-inflated negative binomial models were adopted to predict LOS and the numbers of hospitalisation stays and outpatient visits, and negative binomial models were used to predict the number of physician office visits. For outpatient, non-drug medical, prescription drug and total medical costs, we restricted our sample to positive observations and used generalised linear models (GLMs) with $\log$ link and gamma distribution for estimation. For hospitalisation costs, we adopted a two-part model, since only approximately $20 \%$ of our study sample had hospitalisations. In this model, the first part was a logistic regression model to predict the likelihood of having a non-zero hospitalisation costs, and the second part of the model used GLM to estimate the non-zero hospitalisation costs. All statistical analyses were conducted using SAS V. $9.3^{25}$ or Stata V. $14^{26}$ where applicable.

\section{Patient and public involvement statement}

Patients and or public were not involved.

\section{RESULTS}

There were 6045 eligible Medicare beneficiaries who met our sample selection criteria. The average age of our study cohort was 74.6 years old. The majority identified as non-Hispanic white $(83.8 \%)$, with the rest $(16.2 \%)$ identifying as non-Hispanic black, Hispanic or Asian (table 1).

Table 2 shows the summary statistics for treatment variables and outcome variables (including non-drug healthcare utilisation and healthcare costs) over the 5-year course of treatment. The average MPR was the highest in the first year of treatment (79\%) and lowest in the fifth year $(54 \%)$ of treatment. The percentage of patients who were adherent in each of the 5 years (ie, MPR $>=80 \%$ ) ranged from $39.4 \%$ to $64.2 \%$. On average, about $20 \%$ of surviving patients each year had at least one hospitalisation event, while about $90 \%$ had at least one outpatient visit, and approximately $99 \%$ had at least one physician office visit. Among those with at least one hospitalisation in each year, the mean number of inpatient stays was 1.9-2.2 and mean LOS was 22.0-24.4 days. The mean annual total healthcare costs ranged from US $\$ 12970$ to US\$21 431 over the 5 years of AI treatment (this translates to US\$14957 to US\$24714 in 2021 US dollars), while medication costs accounted for $22 \%-31 \%$ of the total healthcare costs each year (US\$2875-US\$6664).

Table 3 presents the unadjusted annual non-drug healthcare utilisation and costs in adherent and nonadherent Medicare beneficiaries across their 5 years of treatment. For year 3 through year 5, a significantly lower percentage of adherent beneficiaries had at least one hospitalisation compared with non-adherent beneficiaries. Among those with hospitalisations, however, neither number of stays nor mean LOS were statistically significant different in any year. Conversely, the per cent of adherent beneficiaries who had any outpatient visits was higher than the per cent of non-adherent beneficiaries in the fourth year and lower in the fifth year, while no statistically significant differences in the rest of the years. Across the 5 years, adherent patients (MPR greater or equal to $80 \%$ ) had consistently fewer physician office visits than non-adherent patients. In general, adherent beneficiaries had lower medical costs, but higher medication costs than non-adherent beneficiaries, which led to slightly higher total healthcare costs among adherent beneficiaries compared with non-adherent beneficiaries.

Results of adjusted models predicting the association between MPR and non-drug healthcare utilisation and costs are shown in table 4 . The results showed that the increased MPR was statistically significantly associated with fewer hospitalisations, shorter LOS, fewer outpatient visits (including emergency room visits) and fewer physician office visits. MPR was also positively associated with medication costs and negatively associated with total medical costs. However, the difference in total healthcare costs is not statistically significant. Table 5 shows the results of adjusted models using the alternative indicator of adherence instead of the continuous MPR measure. Table 5 results indicate that healthcare utilisation measures are always lower for adherent beneficiaries compared with non-adherent beneficiaries. Adherent beneficiaries had fewer hospitalisations $(0.35$ 
Table 5 Adjusted healthcare utilisation and costs for Medicare beneficiaries' adherent and non-adherent to hormone therapy over the full course of treatment

\begin{tabular}{|c|c|c|c|c|}
\hline Variables & Adherent* & Non-adherent & Difference & $\mathrm{P}+$ \\
\hline Number of hospital days & $4.19(0.16)$ & $4.89(0.18)$ & $-0.70(0.22)$ & $<0.01$ \\
\hline Number of outpatient visits & $6.45(0.05)$ & $6.54(0.06)$ & $-0.09(0.08)$ & NS \\
\hline \multicolumn{5}{|l|}{ Healthcare costs } \\
\hline \multicolumn{5}{|l|}{ Medicare payment amount } \\
\hline Total healthcare costs & $16246(164)$ & $16077(200)$ & $169(262)$ & NS \\
\hline Medical costs & $10310(152)$ & $12551(195)$ & $-2,242(249)$ & $<0.001$ \\
\hline Pharmacy costs & $5891(46)$ & $3577(37)$ & $2314(61)$ & $<0.001$ \\
\hline
\end{tabular}

*The prediction model controlled for other covariate, full results see Supplementary Material (online supplemental appendix D).

†NS stands for not significant.

vs $0.43, \mathrm{p}<0.001)$ and fewer physician office visits $(25.16$ vs 26.17, $\mathrm{p}<0.001)$ and shorter LOS during hospitalisation (4.19 vs 4.89, $\mathrm{p}<0.01)$. On average, Medicare paid US\$2314 $(\mathrm{p}<0.001)$ more on medications for adherent beneficiaries, but US $\$ 2242(\mathrm{p}<0.001)$ less on total nondrug medical costs. This resulted in no statistically significant difference in total Medicare healthcare costs. Each line of results in tables 4 and 5 was generated by an individual multivariant regression analysis as indicated in the method section. Full results are found in supplementary material (online supplemental appendices C and D).

\section{DISCUSSION}

Our study explored the relationships between HT adherence and non-drug healthcare utilisation and costs among patients with breast cancer. To our knowledge, this is one of the first studies to examine the association of medication adherence and non-drug healthcare utilisation and costs across the full 5 -year course of treatment and among a sample of patients as diverse as that provided by the SEER-Medicare database. We found that patients who were adherent to HT were associated with fewer inpatient, outpatient and physician office visits. Consistent with previous studies, ${ }^{15} 1718$ we also found that patients who were adherent to HT were associated with significant reductions in many types of medical costs as well as total medical costs. Half of the reduction in total medical cost came from savings in hospitalisations. This is expected, since staying on HT for at least 5 years, as clinical guidelines recommend, reduces the likelihood of breast cancer recurrence. From this analysis, we find that adherent patients are more likely to avoid a recurrence of breast cancer and the associated costs for related treatment. Our findings suggest that the added cost of HT adherence is all but offset by the reduced cost for other categories of medical care.

To determine the contingent effect of medication adherence on healthcare utilisation and costs, we included unalterable patient level factors in our models such as age, race and tumour stage at time of diagnosis. These factors are known to be strongly associated with adherence and, thus, also impact utilisation and costs. However, they are not factors that clinicians and policymakers can directly change. Nevertheless, earlier analyses have identified two manageable factors that could improve adherence, and by doing so, impact healthcare utilisation and costs: care coordination for comorbid health conditions and financial help with medication copayments. $^{27} 28$ Systematic care coordination among health service providers to address comorbid health conditions is possible but is usually considered costly to implement. ${ }^{27}$ This study does indicate, however, that the additional cost would be limited to the care coordination itself. The added costs of medication due to higher adherence would be, for the most part, offset by lower non-drug medical costs.

Value-based insurance design (VBID) plans are designed to offer high-value healthcare at reduced out-of-pocket costs (OOPCs) to patients with certain diagnoses and/or socioeconomic status. ${ }^{29}$ Some Medicare Advantage plans have adopted the VBID model to manage beneficiary healthcare costs while maintaining healthcare quality. For example, Medicare Advantage patients with certain chronic diseases may see reduced copayments for medications. ${ }^{29}$ An study from 2020 found that lower OOPCs were associated with enhanced long-term medication treatment among Medicare beneficiaries with breast cancer. ${ }^{28}$ The authors also showed that eliminating cost sharing was associated with improved 
adherence among patients with breast cancer who were Medicare/Medicaid dual eligibles. ${ }^{30}$ By reducing the copayments for these patients, VBID plans aim to improve medication adherence and avoid other costly medical services. The findings from our study further support this concept: improved medication adherence did not result in increased total healthcare use and costs, even though it drove up the pharmacy costs.

The benefit of conducting our study using claims data is that the data contain real-world information on HT adherence and non-drug healthcare utilisation and costs. However, there are also some limitations. First, we used Medicare part D data to calculate MPR to indicate adherence. Filled prescriptions do not necessarily mean that all were consumed by the patient. In addition, our results do not reflect some cases where a patient may have supplementary insurance to cover their medication costs or in the event that a patient switched from AI to other HT medications (ie, tamoxifen). Second, the drug costs were calculated by using the gross drug costs (consisting of ingredient cost, dispensing fee and total amount attributed to sales tax). However, Medicare drug plans may receive rebates from pharmaceutical companies for these medications, which is confidential information. The actual Medicare payment amount for medications may be less than the total of gross drug costs reported. Therefore, it is likely that our study overestimated the pharmacy costs. Third, the costs of breast cancer management may be different throughout years due to advances in the prevention, screening and treatment of breast cancer. We were unable to capture all the impacts of these advances throughout years; however, we included variables representing calendar years to address these concurrent trends. Finally, we do not know if the reduced medical costs and healthcare utilisation were solely associated with better adherence. It is possible that patients who were more adherent to HT treatment were more likely to be adherent to other non-drug treatments and/or have a healthier lifestyle, which could have biased the results away from the null. It would be meaningful for future studies to separate these effects from medication adherence.

\section{CONCLUSIONS}

Our study is one of the first to analyse the association between HT adherence and non-drug healthcare utilisation and costs among Medicare beneficiaries over the full course of treatment. Our results suggested that better adherence is associated with lower healthcare utilisation of all kinds (inpatient, outpatient and physician office visits) and no change in total healthcare costs despite the increased pharmacy costs. Our study also provides insights into the potential benefits of implementing VBID plans among patients with breast cancer to improve their long-term oral medication adherence. Policymakers should consider adherence improvement strategies such as VBID plans given the potential health benefits, and that the costs likely will not surpass the total savings.

Contributors Study concepts: SM, CT, REM. Study design: SM, GAR. Data acquisition: SM, CT. Data analysis and interpretation: SM, GAR, CT, DSS. Statistical analysis: SM, GR. Manuscript preparation: SM, CT, GAR, DSS. Manuscript editing: SM, CT, DSS, REM, GAR. Manuscript review: SM, CT, DSS, REM, GAR. SM acts as the guarantor.

Funding The authors have not declared a specific grant for this research from any funding agency in the public, commercial or not-for-profit sectors.

Competing interests None declared.

Patient consent for publication Not applicable.

Ethics approval The Brandeis Committee for Protection of Human Subjects, operating under Federal wide Assurance number FWA00004408, has deemed the protocol for this study (number 18136) to be exempt from further IRB oversight in accordance with 45 CFR 46.101(b) (4).

Provenance and peer review Not commissioned; externally peer reviewed.

Data availability statement All data relevant to the study are included in the article or uploaded as supplementary information. N/A.

Supplemental material This content has been supplied by the author(s). It has not been vetted by BMJ Publishing Group Limited (BMJ) and may not have been peer-reviewed. Any opinions or recommendations discussed are solely those of the author(s) and are not endorsed by BMJ. BMJ disclaims all liability and responsibility arising from any reliance placed on the content. Where the content includes any translated material, BMJ does not warrant the accuracy and reliability of the translations (including but not limited to local regulations, clinical guidelines, terminology, drug names and drug dosages), and is not responsible for any error and/or omissions arising from translation and adaptation or otherwise.

Open access This is an open access article distributed in accordance with the Creative Commons Attribution Non Commercial (CC BY-NC 4.0) license, which permits others to distribute, remix, adapt, build upon this work non-commercially, and license their derivative works on different terms, provided the original work is properly cited, appropriate credit is given, any changes made indicated, and the use is non-commercial. See: http://creativecommons.org/licenses/by-nc/4.0/.

\section{ORCID iDs}

Siyu Ma http://orcid.org/0000-0001-7269-2884

Donald S Shepard http://orcid.org/0000-0003-2187-0593

\section{REFERENCES}

1 Siegel RL, Miller KD, Jemal A. Cancer statistics, 2020. CA Cancer J Clin 2020;70:7-30

2 Howlader N, Noone AM, Krapcho M. Seer cancer statistics review. Bethesda: National Cancer Institute, 2019.

3 National Cancer Institute. Cancer Trends Progress Report, 2021. Available: https://progressreport.cancer.gov/after/economic_burden [Accessed 18 Nov 2021].

4 Burstein HJ, Temin S, Anderson H, et al. Adjuvant endocrine therapy for women with hormone receptor-positive breast cancer: American Society of clinical oncology clinical practice guideline focused update. J Clin Oncol 2014;32:2255-69.

5 Safaie E, Cancer B. Invasive ductal carcinoma. PET/MR Imaging: Springer, 2018: 67-8.

6 Types of breast cancer: ER positive, HER2 positive, and triple negative, 2012. Available: http://www.webmd.com/breast-cancer/ breast-cancer-typeser-positive-her2-positive

7 Hormone theray for breast cancer, 2012. Available: http://www. cancer.gov/cancertopics/factsheet/Therapy/hormone-therapy-breast

8 Early Breast Cancer Trialists' Collaborative Group (EBCTCG), Davies $\mathrm{C}$, Godwin J, et al. Relevance of breast cancer hormone receptors and other factors to the efficacy of adjuvant tamoxifen: patient-level meta-analysis of randomised trials. Lancet 2011;378:771-84.

9 Burstein HJ, Griggs JJ, Prestrud AA, et al. American Society of clinical oncology clinical practice guideline update on adjuvant endocrine therapy for women with hormone receptor-positive breast cancer. J Oncol Pract 2010;6:243-6.

10 Vrijens F, Stordeur S, Beirens K, et al. Effect of hospital volume on processes of care and 5-year survival after breast cancer: a population-based study on 25000 women. Breast 2012;21:261-6.

11 McCowan C, Shearer J, Donnan PT, et al. Cohort study examining tamoxifen adherence and its relationship to mortality in women with breast cancer. Br J Cancer 2008;99:99.

12 Yood MU, Owusu C, Buist DSM, et al. Mortality impact of less-thanstandard therapy in older breast cancer patients. J Am Coll Surg 2008;206:66-75. 
13 Roebuck MC, Dougherty JS, Kaestner R, et al. Increased use of prescription drugs reduces medical costs in Medicaid populations. Health Aff 2015;34:1586-93.

14 Kennedy-Martin T, Boye KS, Peng X. Cost of medication adherence and persistence in type 2 diabetes mellitus: a literature review. Patient Prefer Adherence 2017;11:1103-17.

15 Roebuck MC, Liberman JN, Gemmill-Toyama M, et al. Medication adherence leads to lower health care use and costs despite increased drug spending. Health Aff 2011;30:91-9.

16 Esposito D, Bagchi AD, Verdier JM, et al. Medicaid beneficiaries with congestive heart failure: association of medication adherence with healthcare use and costs. Am J Manag Care 2009;15:437-45.

17 Boye KS, Curtis SE, Lage MJ, et al. Associations between adherence and outcomes among older, type 2 diabetes patients: evidence from a Medicare supplemental database. Patient Prefer Adherence 2016;10:1573.

$18 \mathrm{Wu}$ J, ZK L. Hormone therapy adherence and costs in women with breast cancer. Am J Pharm Benefits 2013;5:65-70.

19 National Cancer Institute D, Surveillance Research Program. Surveillance, epidemiology, and end results (seer) program research data (1975-2016) 2017.

20 Biggers A, Shi Y, Charlson J, et al. Medicare D subsidies and racia disparities in persistence and adherence with hormonal therapy. $J$ Clin Oncol 2016;34:4398-404.

21 Farias AJ, Du XL, . Association between out-of-pocket costs, race/ethnicity, and adjuvant endocrine therapy adherence among Medicare patients with breast cancer. J Clin Oncol 2017;35:86-95.

22 Hershman DL, Tsui J, Meyer J, et al. The change from brand-name to generic aromatase inhibitors and hormone therapy adherence for early-stage breast cancer. J Nat/ Cancer Inst 2014;106. doi:10.1093/ jnci/dju319. [Epub ahead of print: 2710 2014].

23 Neuner JM, Kamaraju S, Charlson JA, et al. The introduction of generic aromatase inhibitors and treatment adherence among Medicare D enrollees. J Natl Cancer Inst 2015;107. doi:10.1093/jnci/ djv130. [Epub ahead of print: 1205 2015].

24 Riley GF, Warren JL, Harlan LC. Endocrine therapy use among elderly hormone receptor-positive breast cancer patients enrolled in Medicare Part D. Medicare Medicaid Res Rev 2011;1. doi:10.5600/ mmrr.001.04.a04. [Epub ahead of print: 13 Dec 2011].

25 SASInstitutelnc. Inventor SAS/ACCESS $\mathbb{R} 9.4$ interface to ADABAS: reference 2013.

26 StataCorp. Inventor Stata statistical software: release 142015.

27 Cutrona SL, Choudhry NK, Fischer MA, et al. Modes of delivery for interventions to improve cardiovascular medication adherence. Am J Manag Care 2010;16:929.

28 Ma S, Shepard DS, Ritter GA, et al. The impact of the introduction of generic aromatase inhibitors on adherence to hormonal therapy over the full course of 5-year treatment for breast cancer. Cancer 2020;126:3417-25.

29 Chernew ME, Rosen AB, Fendrick AM. Value-Based insurance design: by abandoning the archaic principle that all services must cost the same for all patients, we can move to a high-value health system. Health Affairs 2007;26:w195-203.

$30 \mathrm{Ma}$ S, Shepard DS, Ritter GA, et al. Cost sharing for breast cancer hormone therapy: how do dual eligible patients' copayment impact adherence. PLoS One 2021;16:e0250967. 